\title{
Asymmetric Expansion of Summer Season on May and September in Korea
}

\author{
Chang-Hoi Ho ${ }^{1} \cdot$ Chang-Kyun Park ${ }^{1} \cdot$ Jeongmin Yun ${ }^{1} \cdot$ Eun-Ju Lee ${ }^{2} \cdot$ Jinwon Kim $^{3} \cdot$ Hee-Dong Yoo ${ }^{4}$
}

Received: 9 June 2020 / Revised: 1 September 2020 / Accepted: 8 September 2020 / Published online: 28 September 2020

(C) The Author(s) 2020

\begin{abstract}
Global warming and its associated changes in the timing of seasonal progression may produce substantial ripple effects on the regional climate and ecosystem. This study analyzes the surface air temperature recorded during the period 1919-2017 at seven stations in the Republic of Korea to investigate the long-term changes at the beginning and ending of the summer season and their relationship with the warming trends of spring and autumn. The temperatures at the starting (June 1) and ending (August 31) dates of the past period (1919-1948) advanced by 13 days and delayed by 4 days, respectively, for the recent period (19882017). This asymmetric change was caused by continuous warming in May for the entire period of analysis and an abrupt warming in September in the recent decades. Different amplitudes of the expansion of the western North Pacific subtropical high in May and September are responsible for the asymmetric expansion of the summer season. The projections of surface warming for spring and autumn in Korea used the downscaled grid data of a regional climate model, which were obtained by the Representative Concentration Pathway 8.5 scenario of a general circulation model, and indicated a continuous positive trend until 2100. Larger interannual variability of blooming timing of early autumn flowers than that of late spring flowers may represent the response of the ecosystem to the seasonally asymmetric surface warming. Results suggest that the shift of seasons and associated warming trend have a disturbing effect on an ecosystem, and this trend will intensify in the future.
\end{abstract}

Keywords Surface warming $\cdot$ Seasonal progression $\cdot$ Western North Pacific subtropical high $\cdot$ RCP8.5

\section{Introduction}

Global warming is a well-known phenomenon. Several previous studies have suggested that the frequency of extreme

Responsible Editor: Seok-Woo Son.

Electronic supplementary material The online version of this article (https://doi.org/10.1007/s13143-020-00220-3) contains supplementary material, which is available to authorized users.

Chang-Hoi Ho

hoch@cpl.snu.ac.kr

1 School of Earth and Environmental Sciences, Seoul National University, 1 Gwanak-ro, Gwanak-gu, Seoul 151-747, Republic of Korea

2 School of Biological Sciences, Seoul National University, Seoul, Republic of Korea

3 National Institute of Meteorological Sciences, Korean Meteorological Administration, Jeju, Republic of Korea

4 Busan Regional Office of Meteorology, Korean Meteorological Administration, Busan, Republic of Korea weather events will increase significantly (e.g., Sheffield and Wood 2008; Orlowsky and Seneviratne 2012; Trenberth and Fasullo 2012; Dai 2013). In the Republic of Korea (hereafter Korea), the occurrence and intensity of heat waves have increased in association with the regional warming over East Asia (e.g., Ho et al. 2011; Min et al. 2015; Lee and Lee 2016; Kim et al. 2016). The amplitude of local warming in Korea is greater than the global amplitude, and this warming tendency is projected to continue in the future (An et al. 2011; KMA 2012; Lee et al. 2013; Suh et al. 2016). Tremendous socio-economic losses and rapid changes in natural environments are expected. Accordingly, it is crucial to understand the surface warming in Korea for the observational and model projection periods to prevent potential damages.

Surface warming in Korea is caused by both anthropogenic and natural factors. Owing to the rapid growth of socio-economic activities caused by the industrialization and urbanization of Korea since the 1970s, recent warming might be related to the urbanization and heat island effects (Choi et al. 2003; Chung et al. 2004; Lee and Kim 2008; Jeong et al. 2011; Kim and Kim 2011; 
Kug and Ahn 2013). Kim and Kim (2011) analyzed surface temperature data for the major cities in Korea, such as Seoul, Incheon, and Daegu, and revealed that the surface temperature has substantially increased by more than $1{ }^{\circ} \mathrm{C}$ due to a massive growth of population since the 1970s. Apart from the factors influencing local temperature changes, large-scale climatic variabilities on interannual to decadal timescales, such as the El Niño-Southern Oscillation (ENSO) and Arctic Oscillation (AO), have also influenced the national warming trend (Gong and Ho 2004; Kug et al. 2010; Lee and Julien 2016; Yeo et al. 2018; Park et al. 2020). Considering a significant spatiotemporal variability of surface warming due to the abovementioned factors, the use of long-term observations (at least on a century time scale) is necessary to identify climate changes in Korea.

In Korea, the characteristics of surface warming differ according to seasons. The spring and autumn warming are characterized by quasi-linear trends, whereas an abrupt jump in mean surface air temperature is observed in summer and winter (Kim et al. 2015b; Choi et al. 2018). In addition, the warming rates in winter and spring are higher than in summer and autumn (Jung et al. 2002; Choi et al. 2007; Kug and Ahn 2013; NIMS 2018). Such heterogeneous warming trends during all the seasons may be related to the expansion and/or shift of seasons (Oh et al. 2004). Previous studies have shown the reinforcement of the western North Pacific subtropical high (WNPSH) and the weakening of the Siberian high, which are closely related to the seasonal progressions of summer and winter in Korea (Gong and Ho 2002; Panagiotopoulos and Shahgedanova 2005; Choi and Kim 2019). The atmospheric pressure field changes might alter the beginning and ending dates of seasons. The changes in the timing of plant activity (i.e., plant phenology), such as advanced flowering in spring and delayed leaf coloring in autumn, indicated shifts in the conventional seasons (Ho et al. 2006; Jeong et al. 2011; Park et al. 2017). Therefore, further investigation of seasonal warming, especially in spring and autumn, with a focus on the shift of seasons is needed.

This study investigates the long-term changes at the beginning and end of the summer season and their impact on the warming trend in neighboring seasons (i.e., late spring and early autumn). Ground observations recorded for a century are used. To recognize the environmental factors responsible for warming, we analyze the changes in WNPSH. Future changes in surface warming are projected by the Weather Research and Forecasting (WRF) model's downscaled grid data produced by the Representative Concentration Pathway (RCP) 8.5 boundaries of the Community Earth System Model (CESM). Finally, we discuss the implications of warming on plant phenology in spring and autumn.

\section{Data and Methods}

\subsection{Temperature Observations and Reanalysis Data}

The daily mean surface air temperature data were collected from seven weather stations located in Korea, i.e., Gangneung, Seoul, Incheon, Daegu, Jeonju, Busan, and Mokpo, which recorded data since the early twentieth century (Table 1). This study used the station data available for almost one century (1919-2017) to explore long-term changes. The temperature values were averaged over the stations and used to identify the common temperature trends in Korea. The observations acquired during the Korean War (1950-1953) were excluded from the dataset due to numerous missing values. To investigate the associated environmental changes related to the summer progression, long-term changes in WNPSH were studied by analyzing daily mean geopotential heights, wind fields, and air temperature at $500-\mathrm{hPa}$ obtained from the European Centre for Medium-Range Weather Forecasts Twentieth Century Reanalysis (ERA-20C; Poli et al. 2016) for the period of 1919-2010. The Seoul, Daegu, and Gangneung weather stations recorded the first bloom dates (FBD) of late spring and early autumn flowers since the 1920s. Using these FBD long-term data of Robinia pseudoacacia in the late spring and Cosmos bipinnatus in early autumn during the overlapping observation period (Seoul and Daegu from 1935 to 2017, Gangneung from 1935 to 2007), the response of terrestrial ecosystems to the observed changes in the summer progression was examined. We defined the beginning and ending dates of the seasons in the past period by a rule of thumb in meteorology: from December 1 to February 28 for winter, from March 1 to May 31 for spring, from June 1 to August 31 for summer, and from September 1 to November 30 for autumn.

\subsection{Downscaled Grid Temperature Data}

The high-resolution global climate model (CESM) and regional climate model (WRF) were employed to project future temperature changes in Korea. A fully coupled simulation was conducted using the CESM version 1 at $0.9^{\circ} \times 1.25^{\circ}$ spatial resolution with 27 vertical layers of sigma-pressure coordinates. After 700 years of spin-up, the model was prescribed by historical forcing for the period of 1850-2005 and future forcing under the RCP8.5 scenario for 2006-2100, in which no action was taken to limit carbon emissions. The CESM simulation generated monthly, daily, and six-hourly datasets for 250 years. The six-hourly dataset was used for the WRF dynamical downscaling as a lateral boundary and for initial conditions from 1980 to 2099. The physical parameterization schemes of WRF were described in Kim et al. (2015a). From the WRF dynamical downscaling, a dataset with a total of 120 years of daily and six-hourly climate variables were 
Table 1 Information of seven weather stations in Korea

\begin{tabular}{|c|c|c|c|c|}
\hline $\begin{array}{l}\text { Station number } \\
\text { (City) }\end{array}$ & Latitude $\left({ }^{\circ} \mathrm{N}\right)$ & Longitude $\left({ }^{\circ} \mathrm{E}\right)$ & $\begin{array}{l}\text { Elevation } \\
\text { (unit: m) }\end{array}$ & Start year of observation \\
\hline 47105 & 37.75 & 128.88 & 26.0 & 1912 \\
\hline \multicolumn{5}{|l|}{ (Gangneung) } \\
\hline 47108 & 37.57 & 126.95 & 85.8 & 1908 \\
\hline \multicolumn{5}{|l|}{ (Seoul) } \\
\hline 47112 & 37.48 & 126.62 & 68.2 & 1904 \\
\hline \multicolumn{5}{|l|}{ (Incheon) } \\
\hline 47143 & 35.88 & 128.62 & 53.4 & 1909 \\
\hline \multicolumn{5}{|l|}{ (Daegu) } \\
\hline 47146 & 35.82 & 127.15 & 61.4 & 1919 \\
\hline \multicolumn{5}{|l|}{ (Jeonju) } \\
\hline 47159 & 35.10 & 129.03 & 72.4 & 1904 \\
\hline \multicolumn{5}{|l|}{ (Busan) } \\
\hline 47165 & 34.82 & 126.38 & 38.0 & 1906 \\
\hline (Mokpo) & & & & \\
\hline
\end{tabular}

generated. The dataset had $30-\mathrm{km}$ horizontal resolution, and 27 vertical layers were spread out over East Asia. Herein, the daily mean surface air temperature in Korea was mainly analyzed. The biases of surface air temperature in the CESMWRF model results were evaluated by the observations from 61 weather stations located in Korea over the period 19802017. In addition, both simulated daily mean geopotential heights and wind fields at 500-hPa over north western pacific were also used to estimate changes in the WNPSH in the present and future.

\section{Asymmetric Seasonal Warming and Related Large-Scale Environments}

Figure 1 displays the interannual variations of the observed spring (March-May) and autumn (September-November) temperatures averaged over seven stations during the period 1919-2017. The warming trend of spring $\left(0.28^{\circ} \mathrm{C} \mathrm{decade}^{-1}\right)$ is greater than that of autumn $\left(0.19^{\circ} \mathrm{C}\right.$ decade $\left.^{-1}\right)$ for all of the analyzed years. This is consistent with the previous studies on the temperature changes in recent decades (e.g., Jung et al. 2002; Kug and Ahn 2013). The enhanced spring warming trend has been commonly observed during both the recent decades and over the last century. It implies that asymmetric trends which may be related to the global warming are unlikely to be induced by recent urbanization and/or specific dominant phases of large-scale climatic variabilities like ENSO and AO.

Figure 2 shows the changes in the probability distribution of daily temperature averaged over seven stations in spring and autumn. The temperature in both seasons increased during recent period (1988-2017) compared to the past period (1919-1948), indicating an apparent global warming tendency. It is noteworthy that the probability of high temperatures (above $15^{\circ} \mathrm{C}$ ) increased predominantly in spring and not in autumn. Since such high temperatures are observed throughout summer, the change in the high-temperature probability between the seasons may represent advancement of summer, which now begins in May, and relatively insignificant retreat of summer, which now tends to end in September. Similarly, the probability of low temperatures (below $5^{\circ} \mathrm{C}$ ), which are usually observed in winter, much decreased in spring than in autumn, implying substantial advancement of winter, which now ends in February, and slight retreat of winter, which begins in December.

To quantify the changes in the progression of seasons, we focused on the changes that occurred at the beginning and end

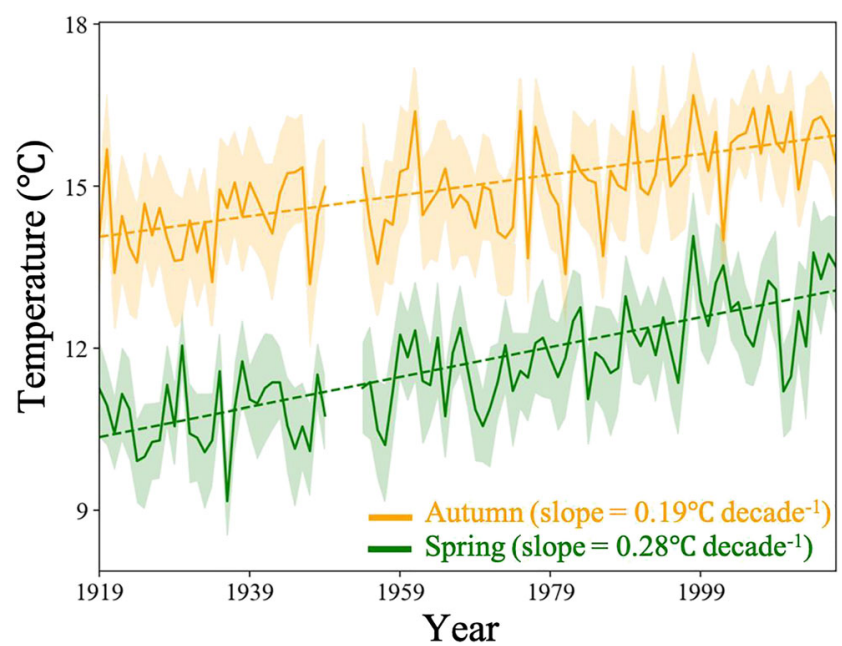

Fig. 1 Interannual variations in the mean surface air temperature in spring (averaged from March to May; in green) and autumn (averaged from September to November; in orange) averaged over seven stations. Variations within one standard deviation are represented by shaded areas. Dashed lines indicate the linear regression line 
Fig. 2 Probability distributions of the daily mean surface air temperature in spring (from March to May) and autumn (from September to November) averaged over seven stations for the past (1919-1948) and present (1988-2017) periods (a)

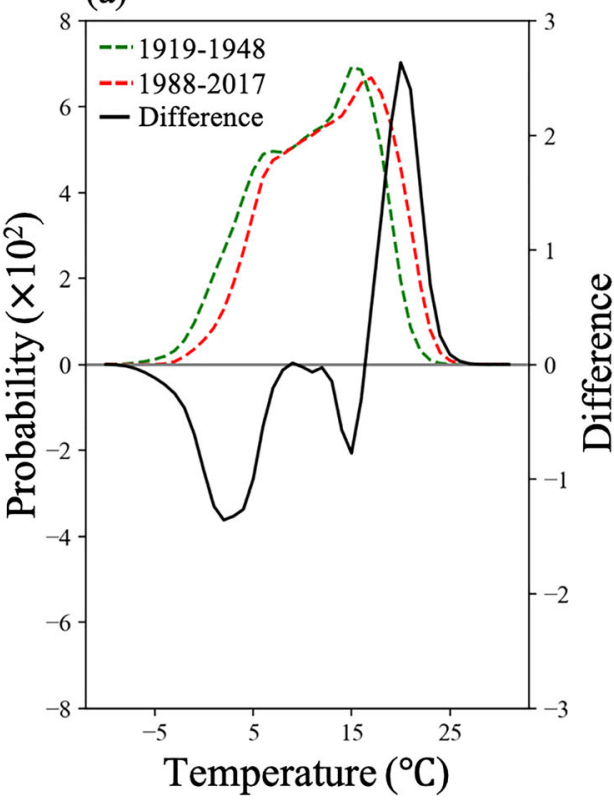

(b)

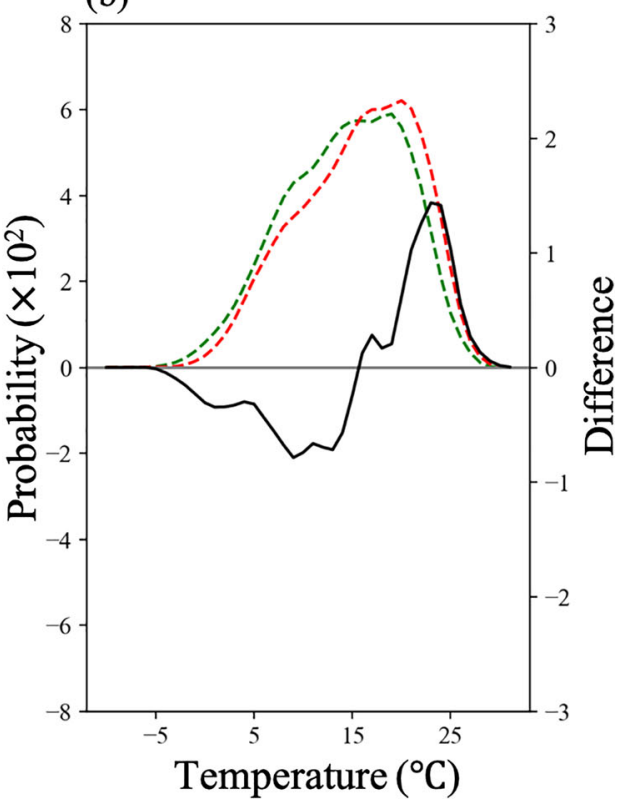

of these seasons. Figure 3 shows the annual variation in daily mean temperature averaged over seven stations during the past and recent periods. The variation was smoothed by the 31-day running mean to minimize the day-to-day temperature variability (thick lines in Fig. 3). The comparative analysis revealed that the temperatures for the period of January to June have increased significantly than those for the period of September to December. Due to the asymmetric warming trend, the temperatures in the past period at the beginning of spring (March 1) and summer (June 1) are met 18 and 13 days earlier, respectively, than those in the recent period. However, the temperatures in the past period at the beginning of autumn (September 1) and winter (December 1) are met 4 and 6 days later, respectively, than those in the recent period. Summing up, Figs. 2 and 3 represent the observed warming trends that differ for spring and autumn and are associated with the asymmetric progression of seasons.

Figure 4 depicts the interannual variation in the anomalies of the daily mean temperature averaged over seven stations. Figure $4 \mathrm{a}$ demonstrates that although large interannual variability is noted, the warming trend has been predominant in recent decades for most of the times. When the smoothed signals are examined based on the climatological time scale with the 31-year running mean, cold anomalies are clearly identified in the months of May in the 1930s, whereas consistent warm anomalies started from the 1960s. On the contrary, cold anomalies in the months of September in the 1930s are unclear, whereas the September consistent warm anomalies started from the 1980s (Fig. 4b). These different warming trends obtained for the months of May and September indicate that the start of summer has advanced even faster than the end of summer has retreated (Fig. 3). As for the consistent warm anomalies for the months of February and December, they both emerged in the 1970s, and the magnitude of warming in February is much higher than that in December. As such, contrary to the summer, the asymmetric changes in the dates of winter beginning and ending are related not to the temporal characteristics of the warming trend but rather to greater warming in February than in December. Summarizing, changes in the beginning date of summer are mainly caused by
Fig. 3 Variations in the daily mean surface air temperature averaged over seven stations for the past (1919-1948) and present (1988-2017) periods (dashed lines). Solid lines represent the 31-day running mean. Variations within one standard deviation are represented by shaded areas

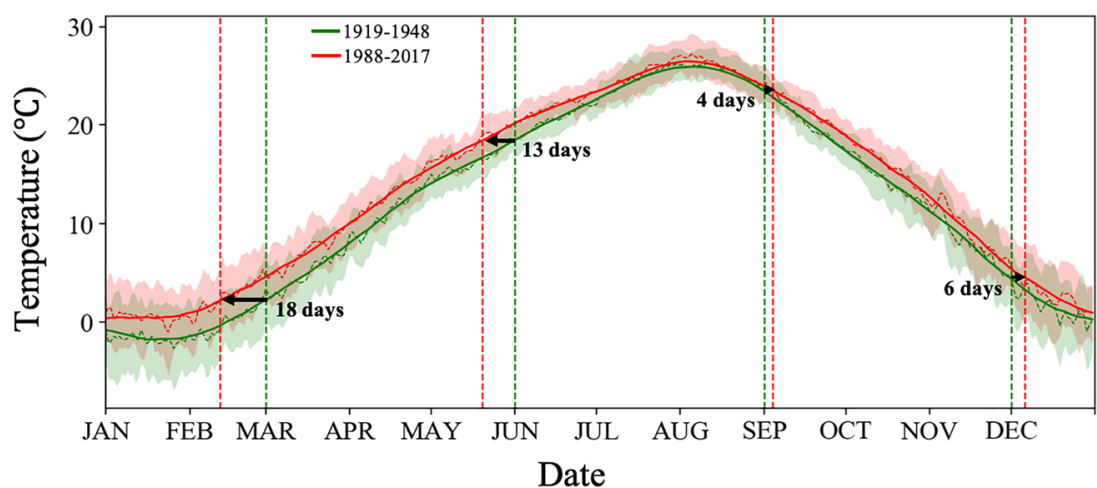


Fig. 4 (a) Anomalies of the daily mean surface air temperature averaged over seven stations for each year. (b) Representation of the 31-year running mean of (a). The boundaries of spring (March 1 and May 31) and autumn (September 1 and November 30) are depicted by dashed lines

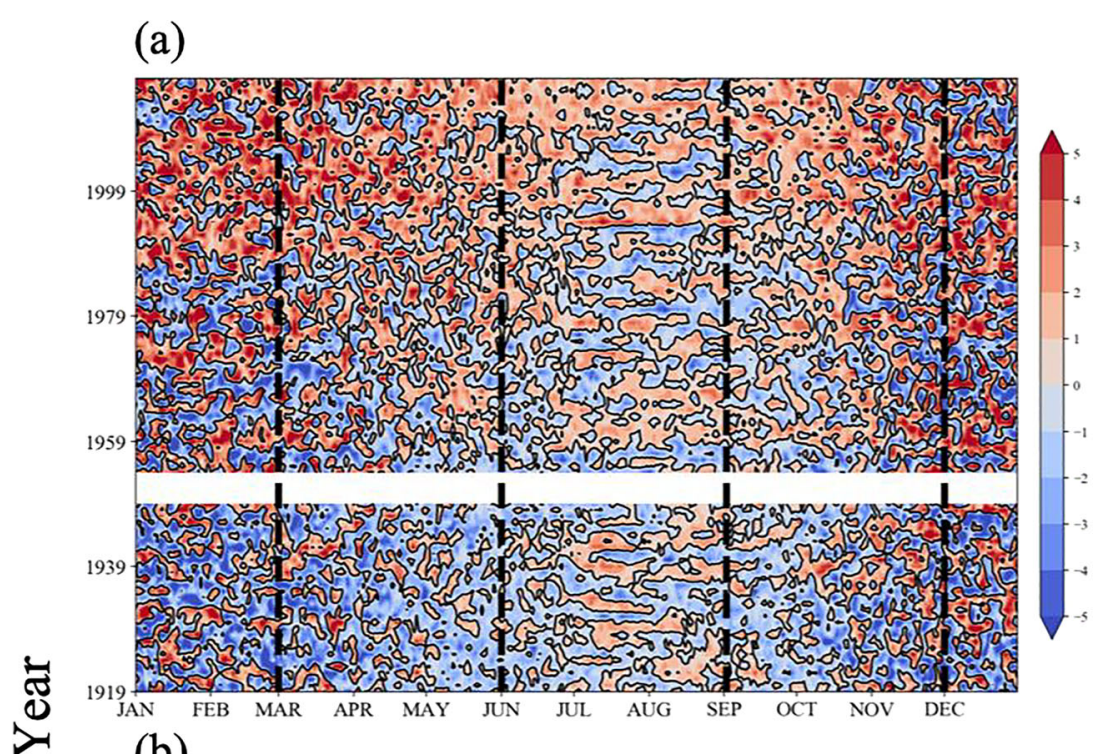

(b)

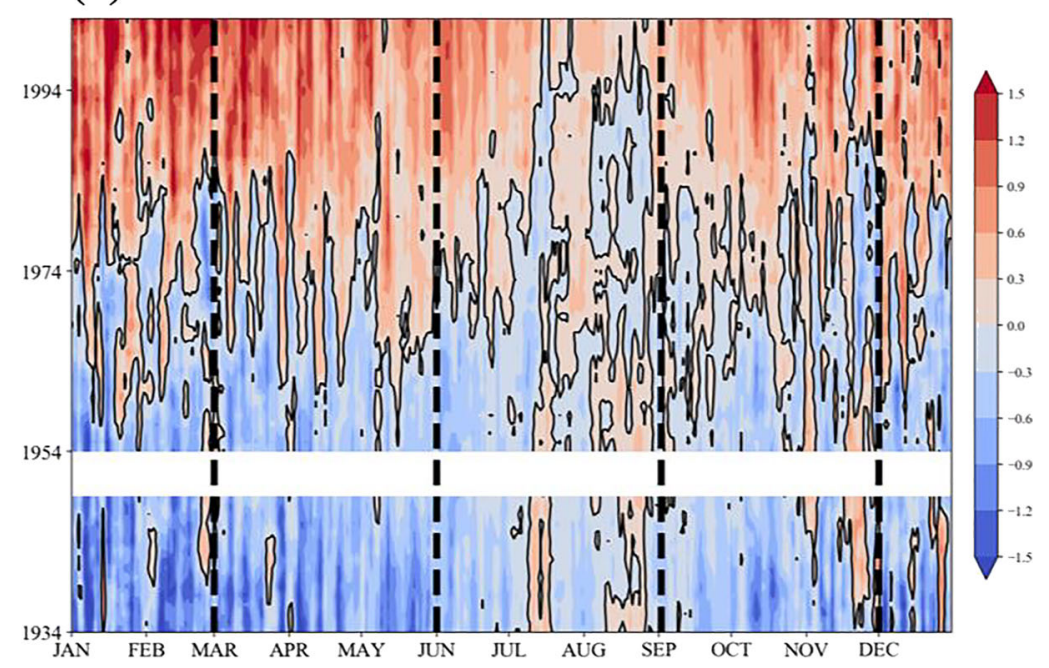

Date consistent warming in May, which has started and continues from the past period, whereas changes in the ending date of summer and both the beginning and ending dates of winter are affected by the recently emerged warming. Thus, the aforementioned different long-term warming trends between spring and autumn (Fig. 1) are probably caused by the long-term asymmetric shift of summer.

WNPSH is a key physical factor for the seasonal progression of summer in Korea as it influences the variations in the East Asian summer monsoon (e.g., Wang et al. 2000; Lee et al. 2005). Herein, the variations in WNPSH by the decade are represented by the $5850-\mathrm{m}$ line of the mean $500-\mathrm{hPa}$ geopotential height averaged for each May 19-31 and September 1-13. These discrepancies in WNPSH are then scrutinized to find the associated environmental variations for the heterogeneous change in the seasonal progression of summer (Fig. 5). The 5850-m line for WNPSH is defined by a mean value that varies between 5880 and $5820 \mathrm{~m}$ and is related to the mature and developing/decaying phases of WNPSH for the summer season in Korea. The 13-day average period is based on the change in the beginning date of summer (Fig. 3). WNPSH expanded considerably toward the East Asian region at the beginning of summer during the 1920s1960s (Fig. 5a). Although it temporarily shrunk in the 1970s, another immense expansion was observed between the 1980s and 2000s. Namely, the WNPSH has been significantly expanded during the century time scale analysis period. The considerable expansion of WNPSH indicates the earlier start of summer monsoon in the East Asian regions, which can be identified by the much inflow of the relatively warm air in the lower-latitude to Korea in the present decades compared to the past decades (Fig. S1). This results a great advancement of the beginning date of summer and warming trend in May over Korea (Figs. 3 and 4). In contrast, the amplitude of the 
(a)

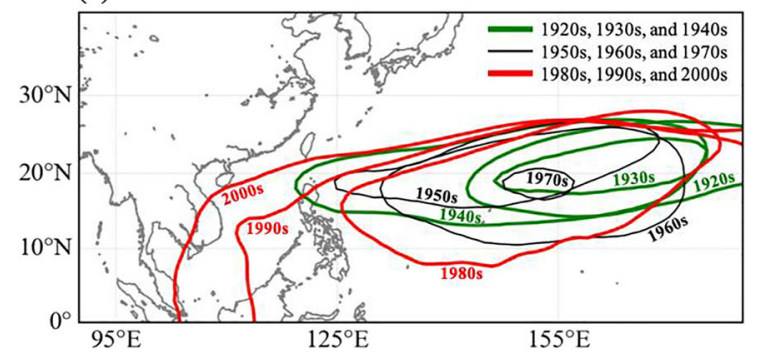

(b)

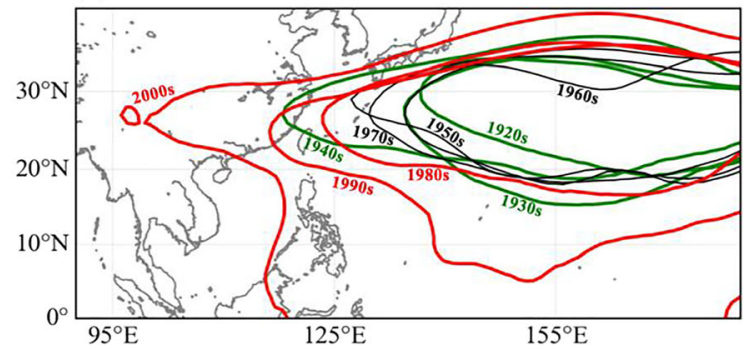

Fig. 5 The 5850-m lines of the mean 500-hPa geopotential height averaged (a) from May 19 to May 31, and (b) from September 1 to September 13 for each decade

expansion of WNPSH at the end of summer was insignificant during the 1920s-1970s and became noticeable only after the 1980s (Fig. 5b). The emerged September warming trend (Fig. 4) may be related to the change in WNPSH. Accordingly, the different amplitudes of the expansion of WNPSH toward the East Asian region between May and September likely influence the asymmetric change in the seasonal progression of summer.

\section{Future Projection}

Future changes in surface temperature in Korea were projected using the RCP8.5 scenario. The reliability of the simulation results of the CESM-WRF model was evaluated by comparing the results with the observations from 61 weather stations before the completion of the future projection analysis. The simulated annually averaged surface air temperature represents well the spatial distribution of the observed annually averaged surface air temperature during spring (correlation coefficient $r=0.64, p<0.01)$ and autumn $(r=0.82, \mathrm{p}<$ 0.01) for the overlapping period from 1980 to 2017 (Fig. S2). The climatological value of the simulated surface air temperature $\left(14.2^{\circ} \mathrm{C}\right)$ is similar to the observed value $\left(14.3^{\circ} \mathrm{C}\right)$ in autumn. However, the model tends to underestimate the climatological surface air temperature in spring by $2^{\circ} \mathrm{C}$ with a simulated value of $9.8^{\circ} \mathrm{C}$ lower than an observed value of $11.8^{\circ} \mathrm{C}$. Therefore, we corrected the model biases by applying the bias-correction method by Ho et al. (2012) to all of the model grid cells where the weather stations are located (Fig. S2). The bias-corrected model simulation results with daily scales were used for future projections.

Figure 6 presents the interannual variations of seasonally averaged surface air temperature in Korea for the present and future periods. For comparison with previous results obtained at the temperature of seven stations, the present period was defined as the period from 1988 to 2017 in the analysis of model results. For the present period, warming trends of 0.35 and $0.33^{\circ} \mathrm{C}$ decade ${ }^{-1}$ were identified for spring and autumn, respectively, at the 61 stations (red and black lines in Fig. 6a). The model consistently simulated the spring and autumn warming trends of 0.35 and $0.30^{\circ} \mathrm{C}$ decade $^{-1}$, respectively (orange and green lines in Fig. 6a). For the future period (2018-2099), the model projections indicate that warming will intensify by 0.56 and $0.45^{\circ} \mathrm{C}$ decade $^{-1}$ in spring and autumn, respectively. The asymmetric warming trends are caused by warming of more than $0.50^{\circ} \mathrm{C} \mathrm{decade}{ }^{-1}$ in all spring months and relatively weak warming of $0.42^{\circ} \mathrm{C}$ decade $^{-1}$ in October and $0.30^{\circ} \mathrm{C}$ decade $^{-1}$ in November (Fig. 6b,c). However, strong warming of $0.65^{\circ} \mathrm{C}$ decade $^{-1}$ is expected in September, suggesting the warming trend that started in 1980 s will continue in the future. The steepest future warming trend is associated with significant expansion of WNPSH in September (Fig. S3). Our model projected that ridgeline of an anticyclonic circulation at 500-hPa located over the western North Pacific extends further west to $135^{\circ} \mathrm{E}$ and $130^{\circ} \mathrm{E}$ in the middle (2030-2059) and end (2070-2099) of the twentyfirst century from $140^{\circ} \mathrm{E}$ in the present period. The variable future warming patterns are expected to be associated with the changes in the beginning and ending dates of seasons (different from the ones observed in Fig. 3).

Figure 7 shows annual variations in the simulated daily temperature averaged within the grid boxes over Korea for the present period and middle and end of the twenty-first century. Our model projects that the dates of the beginning and end of summer will be advanced by 10 days and delayed by 12 days in the middle of the twenty-first century in comparison to the present period, respectively. The summer progression will be amplified symmetrically with 24 days of advancement and 23 days of delay at the beginning and end of summer, respectively. The symmetric seasonal expansion in the twenty-first century is related to the accelerated summer warming since $2000 \mathrm{~s}$. In the twentieth century, averaged over the seven stations, the summer warming rate $\left(0.01^{\circ} \mathrm{C}\right.$ de$\left.\mathrm{cade}^{-1}\right)$ is lower than the annual warming rate $\left(0.16^{\circ} \mathrm{C}\right.$ de$\left.\operatorname{cade}^{-1}\right)$. This tendency was reversed at the turn of the century; since the $2000 \mathrm{~s}$, the summer warming rate is $0.44^{\circ} \mathrm{C} \mathrm{decade}^{-1}$ and the annual warming rate is $0.18^{\circ} \mathrm{C}$ decade $^{-1}$, indicating a strong warming in the summer mean compared to the annual mean. The present model projects that the summer warming rate $\left(0.68^{\circ} \mathrm{C}\right.$ decade $\left.^{-1}\right)$ will be greater than the annual warming rate $\left(0.56^{\circ} \mathrm{C}\right.$ decade $\left.^{-1}\right)$ throughout the future period 


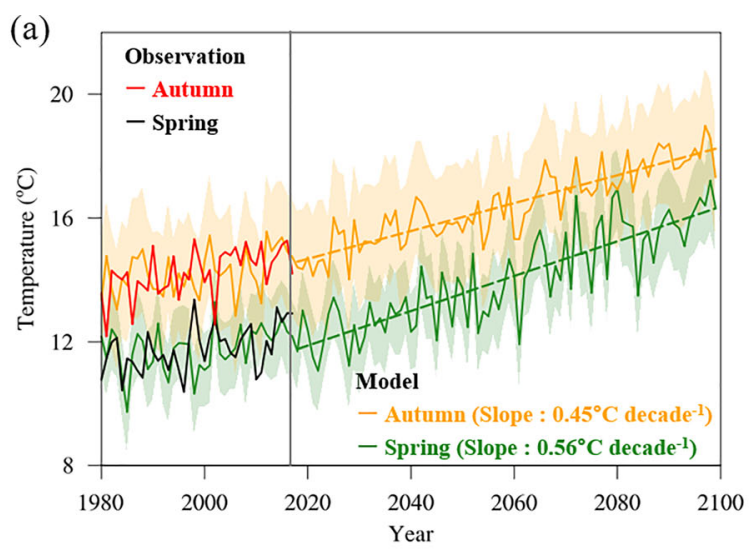

(b)

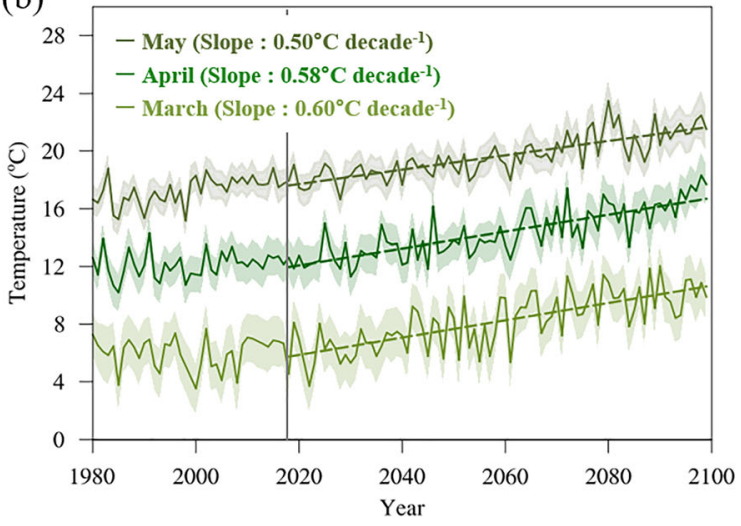

Fig. 6 (a) Interannual variations of the observed and simulated daily mean surface air temperature in spring (averaged from March to May; in green) and autumn (averaged from September to November; in orange) over Korea. Variations within one standard deviation of the temperature

(2018-2099). These results are consistent with previous studies which suggested an acceleration of the summer warming trend resulted from an increase in the mean temperature as well as frequency and magnitude of heatwave (Min et al. 2015; Choi and Lee 2019; Im et al. 2019). Conversely, considerable changes are projected for the beginning date of winter (11 and 24 days) than those for the ending date of winter (6 (c)

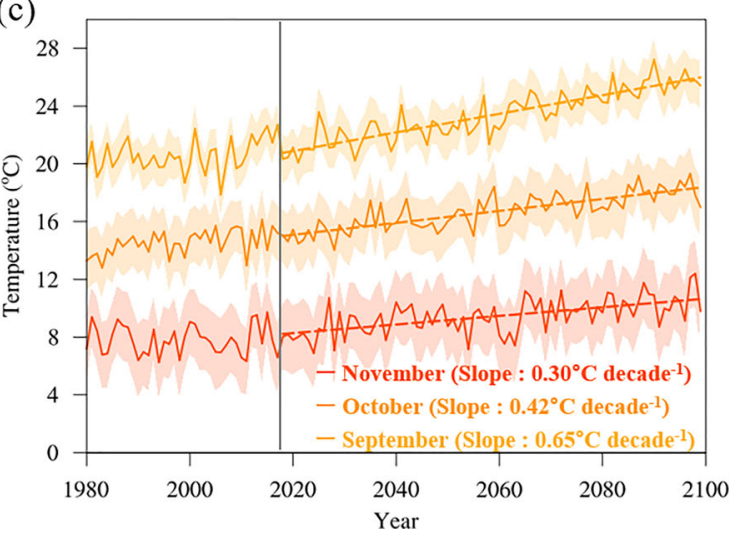

in stations or model grids are represented by shaded areas. Dotted lines represent the regression lines of the simulated temperature for the future period (2018-2099). (b) Same as (a) for each month during spring. (c) Same as (a) for each month during autumn

and 15 days) for the middle and end of the twenty-first century, respectively. These results suggest that the asymmetric winter progression will lead to greater warming in March with $0.60^{\circ} \mathrm{C}$ decade $^{-1}$ (Fig. 6b) than in November with $0.30^{\circ} \mathrm{C}$ decade $^{-1}$ (Fig. 6c). Therefore, the difference between the surface air temperatures in spring and autumn is projected to increase in the future.

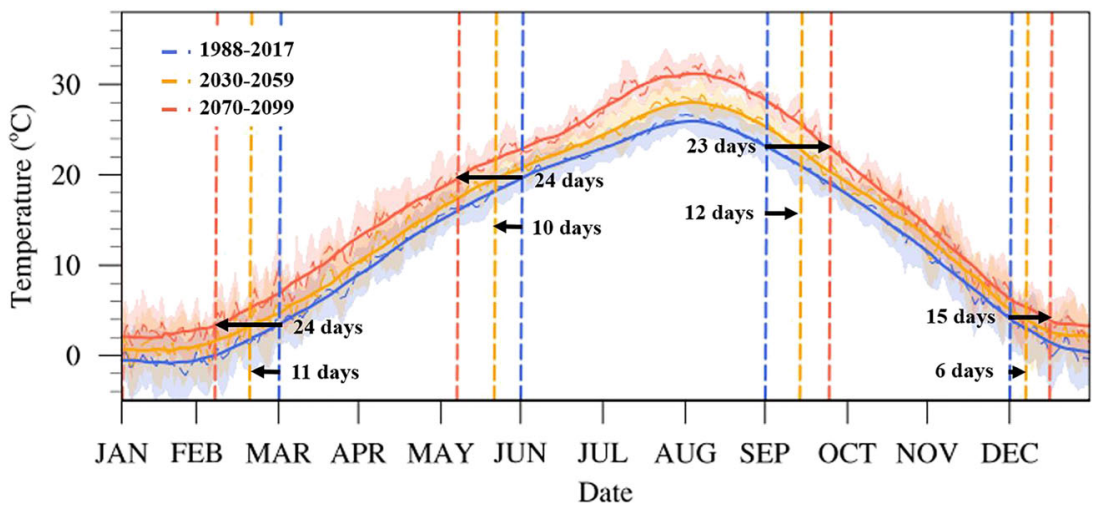

Fig. 7 Variations in the simulated annually averaged daily mean surface air temperature over Korea for the present period (1988-2017; in blue) and middle (2030-2059; in yellow) and end (2070-2099; in red) of the twenty-first century. Solid lines represent the 31-day running mean.

Variations within one standard deviation of the temperature in model grids are represented by shaded areas. Vertical dotted lines indicate the beginning and ending dates of spring and autumn for each period 

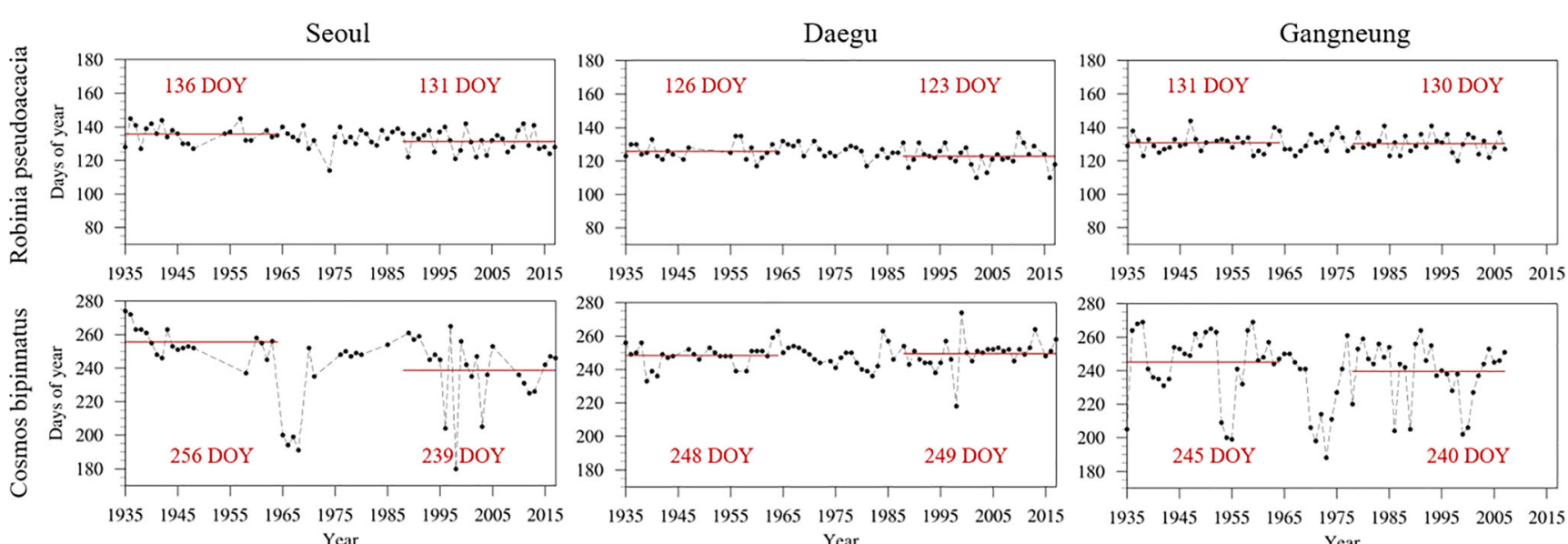

Fig. 8 Interannual variations in the first bloom dates of Robinia pseudoacacia and Cosmos bipinnatus at the Seoul, Daegu, and Gangneung stations

\section{Summary and Discussion}

This study presented the asymmetric changes in the seasonal progression of summer and its effects on the spring and autumn warming trends using long-term observations in Korea. The May warming trend emerged earlier and has been more consistent than that of September, making the advancement of the beginning date of summer greater than the retreat of its ending date. This asymmetry is associated with the expansion of WNPSH toward the East Asian region in May greater than that in September. Due to the asymmetric change in the seasonal progression of summer, the warming trend in spring has been more significant than that in autumn during the last century. The CESM/WRF model projected that the asymmetric warming trends for spring and autumn would continue in the twenty-first century. However, the more pronounced spring warming trend was associated with greater advancement of the ending date of winter, and it was not related to the summer progression differing from the results of observation.

Notice that plant phenology is the timing of plant activity. Phenological events are sensitive to the variations in climate variables, especially to variations in temperature (Ho et al. 2006; Jeong et al. 2009; Park et al. 2017). Therefore, it is suggested that the observed asymmetric warming trends in spring and autumn during the last century affected the spring and autumn plant phenology in Korea. We focused on the long-term changes in FBD of Robinia pseudoacacia and Cosmos bipinnatus from 1935 to 2017 (2007 for Gangneung) acquired at the Seoul, Daegu, and Gangneung stations (Fig. 8). Earlier blooming dates of Robinia pseudoacacia were noted for all of the stations from 1988 to 2017 than that from 1935 to 1964 with a rage of 1 to 5 days. The first bloom timing of Cosmos bipinnatus also advanced at the Seoul and Gangneung stations by 17 and 5 days, respectively. However, FBD of Cosmos bipinnatus shows an interannual variability of 8-21 days, which is larger than that of Robinia pseudoacacia with a range of 5 to 6 days at all of the stations. Different phenological patterns are interpreted to be associated with the continued strong warming in spring and irregular weak warming in late summer and early autumn (Fig. 4). The projected warming changes in spring and autumn are expected to disturb the conventional life cycle of terrestrial ecosystems in Korea in the future. Therefore, continuous monitoring of sub-seasonal changes in the warming trend is required.

Acknowledgments This work was funded by the Korea Ministry of Environment as part of the "Climate Change Correspondence Program.

Open Access This article is licensed under a Creative Commons Attribution 4.0 International License, which permits use, sharing, adaptation, distribution and reproduction in any medium or format, as long as you give appropriate credit to the original author(s) and the source, provide a link to the Creative Commons licence, and indicate if changes were made. The images or other third party material in this article are included in the article's Creative Commons licence, unless indicated otherwise in a credit line to the material. If material is not included in the article's Creative Commons licence and your intended use is not permitted by statutory regulation or exceeds the permitted use, you will need to obtain permission directly from the copyright holder. To view a copy of this licence, visit http://creativecommons.org/licenses/by/4.0/.

\section{References}

An, S.I., Ha, K.J., Seo, K.H., Yeh, S.W., Min, S.K., Ho, C.H.: A review of recent climate trends and causes over the Korean peninsula. Clim. Chan. Res. 2, 237-251 (2011)

Choi, N., Lee, M.-I.: Spatial variability and long-term trend in the occurrence frequency of heatwave and tropical night in Korea. AsiaPacific J. Atmos. Sci. 55(1), 101-114 (2019)

Choi, W., Kim, K.Y.: Summertime variability of the western North Pacific subtropical high and its synoptic influences on the east Asian weather. Sci. Rep. 9, 7865 (2019) 
Choi, W., Ho, C.H., Kim, M.K., Kim, J., Yoo, H.D., Jhun, J.G., Jeong, J.H.: Season-dependent warming characteristics observed at 12 stations in South Korea over the recent 100 years. Int. J. Climatol. 38, 4092-4101 (2018)

Choi, B.C., Kim, J., Lee, D.G., Kysely, J.: Long-term trends of daily maximum and minimum temperatures for the major cities of South Korea and their implications on human health. Atmos. 17, 171-183 (2007) (In Korean)

Choi, Y., Jung, H.S., Nam, K.Y., Kwon, W.T.: Adjusting urban bias in the regional mean surface temperature series of South Korea, 1968 99. Int. J. Climatol. 23, 577-591 (2003)

Chung, U., Choi, J., Yun, J.I.: Urbanization effect on the observed change in mean monthly temperatures between 1951-1980 and 1971-2000 in Korea. Clim. Chang. 66, 127-136 (2004)

Dai, A.: Increasing drought under global warming in observations and models. Nat. Clim. Chang. 3, 52-58 (2013)

Gong, D.Y., Ho, C.H.: Intra-seasonal variability of wintertime temperature over East Asia. Int. J. Climatol. 24, 131-144 (2004)

Gong, D.Y., Ho, C.H.: The Siberian high and climate change over middle to high latitude Asia. Theor. Appl. Climatol. 72, 1-9 (2002)

Ho, C.H., Park, S.J., Jeong, S.J., Kim, J., Jhun, J.G.: Observational evidences of double cropping impacts on the climate in the northern China plains. J. Clim. 25, 4721-4728 (2012)

Ho, C.H., Park, T.W., Jun, S.Y., Lee, M.H., Park, C.E., Kim, J., Lee, S.J., Hong, Y.D., Song, C.K., Lee, J.B.: A projection of extreme climate events in the 21 st century over East Asia using the community climate system model 3. Asia-Pac. J. Atmos. Sci. 51, 103-121 (2011)

Ho, C.H., Lee, E.J., Lee, I., Jeong, S.J.: Earlier spring in Seoul. Korea. Int. J. Climatol. 26, 2117-2127 (2006)

Im, E.-S., Thanh, N.-X., Kim, Y.-H., Ahn, J.-B.: 2018 summer extreme temperatures in South Korea and their intensification under $3^{\circ} \mathrm{C}$ global warming. Environ. Res. Lett. 14(9), 094020 (2019)

Jeong, J.H., Ho, C.H., Linderholm, H.W., Jeong, S.J., Chen, D., Choi, Y.S.: Impact of urban warming on earlier spring flowering in Korea. Int. J. Climatol. 31, 1488-1497 (2011)

Jeong, S. J., Ho, C. H., Kim, K. Y., \& Jeong, J. H.: Reduction of spring warming over East Asia associated with vegetation feedback. Geophys. Res. Lett., 36. (2009)

Jung, H.S., Choi, Y., Oh, J.H., Lim, G.H.: Recent trend in temperature and precipitation over South Korea. Int. J. Climatol. 22, 1327-1337 (2002)

Kim, D.W., Deo, R.C., Chung, J.H., Lee, J.S.: Projection of heat wave mortality related to climate change in Korea. Nat. Hazards. 80, 623637 (2016)

Kim, D., Jin, C.S., Ho, C.H., Kim, J., Kim, J.H.: Climatological features of WRF-simulated tropical cyclones over the western North Pacific. Clim. Dyn. 44, 3223-3235 (2015a)

Kim, Y.H., Kim, M.K., Lau, W.K.M., Kim, K.M., Cho, C.H.: Possible mechanism of abrupt jump in winter surface air temperature in the late 1980s over the northern hemisphere. J. Geophys. Res. Atmos. 120, 474-485 (2015b)

Kim, M.K., Kim, S.: Quantitative estimates of warming by urbanization in South Korea over the past 55 years (1954-2008). Atmos. Environ. 45, 5778-5783 (2011)

Korea Meteorological Administration: Report of future climate change in Korean Peninsula. Research Report 2012-12, 153 pp. (2012)

Kug, J.S., Ahn, M.S.: Impact of urbanization on recent temperature and precipitation trends in the Korean peninsula. Asia-Pac. J. Atmos. Sci. 49, 151-159 (2013)

Kug, J.S., Ahn, M.S., Sung, M.K., Yeh, S.W., Min, H.S., Kim, Y.H.: Statistical relationship between two types of El Niño events and climate variation over the Korean peninsula. Asia-Pac. J. Atmos. Sci. 46, 467-474 (2010)

Lee, J.H., Julien, P.Y.: ENSO impacts on temperature over South Korea. Int. J. Climatol. 36, 3651-3663 (2016)

Lee, W.S., Lee, M.I.: Interannual variability of heat waves in South Korea and their connection with large-scale atmospheric circulation patterns. Int. J. Climatol. 36, 4815-4830 (2016)

Lee, D.K., Cha, D.H., Jin, C.S., Choi, S.J.: A regional climate change simulation over East Asia. Asia-Pac. J. Atmos. Sci. 49, 655-664 (2013)

Lee, S.H., Kim, H.D.: Effects of regional warming due to urbanization on daytime local circulations in a complex basin of the Daegu metropolitan area. Korea. J. Appl. Meteor. Climatol. 47, 1427-1441 (2008)

Lee, E.J., Jhun, J.G., Park, C.K.: Remote connection of the northeast Asian summer rainfall variation revealed by a newly defined monsoon index. J. Clim. 18, 4381-4393 (2005)

NIMS: Report on climate change for 100 years over the Korean Peninsula. NIMS 11-1360620-000132-01, 31 (2018)

Min, S.K., Son, S.W., Seo, K.H., Kug, J.S., An, S.I., Choi, Y.S., Jeong, J.H., Kim, B.M., Kim, J.W., Kim, Y.H., Lee, J.Y., Lee, M.I.: Changes in weather and climate extremes over Korea and possible cause: a review. Asia-Pac. J. Atmos. Sci. 51, 103-121 (2015)

Oh, J.H., Kim, T., Kim, M.K., Lee, S.H., Kim, S.K., Kwon, W.T.: Regional climate simulation for Korea using dynamic downscaling and statistical adjustment. J. Metor. Soc. Japan. 82, 1629-1643 (2004)

Orlowsky, B., Seneviratne, S.I.: Global changes in extreme events: regional and seasonal dimension. Clim. Chang. 110, 669-696 (2012)

Panagiotopoulos, F., Shahgedanova, M.: Observed trends and teleconnections of the Siberian high: a recently declining center of action. J. Clim. 18, 1411-1422 (2005)

Park, T.W., Hong, J.G., Park, D.S.R.: Intra-seasonal characteristics of wintertime extreme cold events over South Korea. Int. J. Climatol. 40, 2639-2658 (2020)

Park, C. K., Ho, C. H., Jeong, S. J., Lee, E. J., \& Kim, J.: Spatial and temporal changes in leaf coloring date of Acer palmatum and Ginkgo biloba in response to temperature increases in South Korea. PloS one, 12. (2017)

Poli, P., Hersbach, H., Dee, D.P., Berrisford, P.: ERA-20C: An atmospheric reanalysis of the twentieth century. J. Clim. 29, 4083-4097 (2016)

Sheffield, J., Wood, E.F.: Projected changes in drought occurrence under future global warming from multi-model, multi-scenario, IPCC AR4 simulations. Clim. Dyn. 31, 79-105 (2008)

Suh, M.S., Oh, S.G., Lee, Y.S., Ahn, J.B., Cha, D.H., Lee, D.K., Hong, S.Y., Min, S.K., Park, S.C., Kang, H.S.: Projections of high resolution climate changes for South Korea using multiple-regional climate models based on four RCP scenarios. Part 1: surface air temperature. Asia-Pac. J. Atmos. Sci. 52, 151-169 (2016)

Trenberth, K.E., Fasullo, J.T.: Climate extremes and climate change: the Russian heat wave and other climate extremes of 2010. J. Geophys. Res. 117, D17103 (2012)

Wang, B., Wu, R., Fu, X.: Pacific-east Asian teleconnection: how does ENSO affect east Asian climate? J. Clim. 13, 1517-1536 (2000)

Yeo, S.R., Yeh, S.W., Kim, Y., Yim, S.Y.: Monthly climate variation over Korea in relation to the two types of ENSO evolution. Int. J. Climatol. 38, 811-824 (2018)

Publisher's Note Springer Nature remains neutral with regard to jurisdictional claims in published maps and institutional affiliations. 